\title{
Association of Serum Zn/Cu Ratio With Handgrip Strength and Hospitalization in Japanese Patients With Type 2 Diabetes
}

\author{
Hidetaka Hamasakia, b, c , Hidekatsu Yanai ${ }^{\mathrm{b}}$
}

\section{To the Editor}

Zinc $(\mathrm{Zn})$ is negatively associated with the incidence of coronary heart diseases in patients with type 2 diabetes [1], and copper $(\mathrm{Cu})$ may also play a pivotal role in the pathogenesis of diabetes [2]. We reported that the serum $\mathrm{Zn} / \mathrm{Cu}$ ratio was positively associated with glycemic control in patients with type 2 diabetes [3]. In another study, patients with type 2 diabetes demonstrated lower handgrip strength, which is a useful predictor of the risk of cardiovascular disease and mortality [4], than those without diabetes [5]. The aim of this study was to examine the association of the serum $\mathrm{Zn} / \mathrm{Cu}$ ratio with handgrip strength and hospitalization for glycemic control in patients with type 2 diabetes.

We conducted a retrospective cohort study on patients with type 2 diabetes who were treated at the National Center for Global Health and Medicine, Kohnodai Hospital, and the study was performed in accordance with the Declaration of Helsinki. Of the 1,303 subjects enrolled, we simultaneously measured the handgrip strength and serum levels of $\mathrm{Zn} / \mathrm{Cu}$ of 131 subjects ( 74 men and 57 women) at baseline. Their mean age, body mass index, and hemoglobin A1c levels were 63.8 \pm 12.7 years, $26.2 \pm 5.8 \mathrm{~kg} / \mathrm{m}^{2}$, and $7.8 \pm 1.9 \%$, respectively. Their mean and median serum $\mathrm{Zn} / \mathrm{Cu}$ ratios were $0.74 \pm 0.25$ and 0.73 , respectively. The serum $\mathrm{Zn} / \mathrm{Cu}$ ratio was positively associated with handgrip strength $(\mathrm{r}=0.279, \mathrm{P}=0.001$, by Spearman's rank correlation coefficient). During the mean follow-up of $469 \pm 425$ days, 55 patients (42\%) were admitted to the hospital for glycemic control. Kaplan-Meier survival analysis confirmed a negative association between the serum $\mathrm{Zn} / \mathrm{Cu}$ ratio and risk of hospitalization for glycemic control ( $\mathrm{P}$ $=0.031)$ (Fig. 1).

To my knowledge, this is the first study to demonstrate a significant association of the serum $\mathrm{Zn} / \mathrm{Cu}$ ratio with handgrip

Manuscript submitted December 20, 2017, accepted December 27, 2017

aHamasaki Clinic, Kagoshima, Japan

${ }^{b}$ Department of Internal Medicine, National Center for Global Health and Medicine Kohnodai Hospital, Chiba, Japan

${ }^{\mathrm{c}}$ Corresponding Author: Hidetaka Hamasaki, Hamasaki Clinic, 2-21-4 Nishida, Kagoshima 890-0046, Japan. Email: hhamasaki78@gmail.com

doi: https://doi.org/10.14740/jem481w strength and hospitalization in patients with type 2 diabetes. Mocchegiani et al [6] reported an unfavorable association of the serum $\mathrm{Cu} / \mathrm{Zn}$ ratio with physical parameters, including handgrip strength and mortality, in elderly subjects. Although serum levels of $\mathrm{Zn}$ and $\mathrm{Cu}$ are influenced by numerous factors, such as the nutritional status and comorbidities [3, 6], an adequate $\mathrm{Zn} / \mathrm{Cu}$ ratio has the potential to ameliorate glycemic control and improve physical functions. However, this is a small-scale, retrospective, observational study; thus, further investigations are needed to understand both the effect of serum $\mathrm{Zn} / \mathrm{Cu}$ ratio on glycemic control and its underlying mechanism of action.

\section{Acknowledgments}

The authors appreciate the support of Clinical Research Center, National Center for Global Health and Medicine Kohnodai

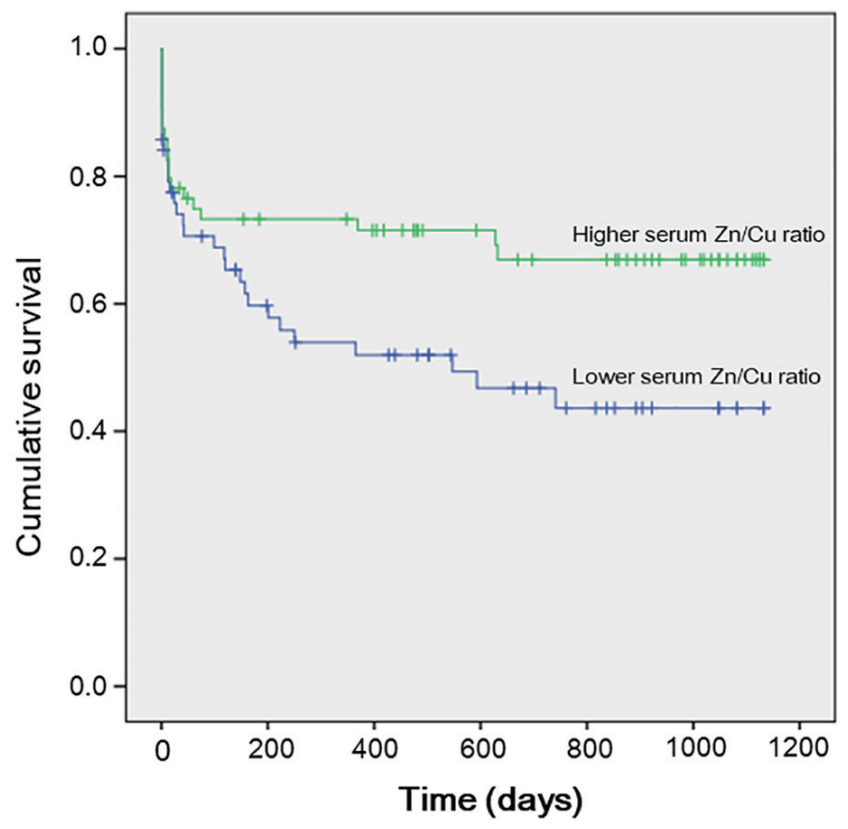

Figure 1. Kaplan-Meier survival analysis of serum $\mathrm{Zn} / \mathrm{Cu}$ ratio for hospitalization. Subjects were divided into higher and lower serum $\mathrm{Zn} / \mathrm{Cu}$ ratio groups on either side of the median. 
Hospital.

\section{Competing Interests}

No potential competing interests relevant to this paper were reported.

\section{References}

1. Chabosseau P, Rutter GA. Zinc and diabetes. Arch Biochem Biophys. 2016;611:79-85.

2. Tanaka A, Kaneto H, Miyatsuka T, Yamamoto K, Yoshiuchi K, Yamasaki Y, Shimomura I, et al. Role of copper ion in the pathogenesis of type 2 diabetes. Endocr J. 2009;56(5):699-706.

3. Hamasaki H, Kawashima Y, Yanai H. Serum Zn/Cu Ratio
Is associated with renal function, glycemic control, and metabolic parameters in Japanese patients with and without type 2 diabetes: a cross-sectional study. Front Endocrinol (Lausanne). 2016;7:147.

4. Hamasaki H, Kawashima Y, Katsuyama H, Sako A, Goto A, Yanai H. Association of handgrip strength with hospitalization, cardiovascular events, and mortality in Japanese patients with type 2 diabetes. Sci Rep. 2017;7(1):7041.

5. Sayer AA, Dennison EM, Syddall HE, Gilbody HJ, Phillips DI, Cooper C. Type 2 diabetes, muscle strength, and impaired physical function: the tip of the iceberg? Diabetes Care. 2005;28(10):2541-2542.

6. Mocchegiani E, Malavolta M, Lattanzio F, Piacenza F, Basso A, Abbatecola AM, Russo A, et al. Cu to $\mathrm{Zn}$ ratio, physical function, disability, and mortality risk in older elderly (ilSIRENTE study). Age (Dordr). 2012;34(3):539552. 